\title{
Pericia médica y discurso científico en los juicios a médicos por aborto. Departamento Judicial de Mar del Plata (1956-1970)
}

Medical Expertise and Scientific Discourse in Abortion Trials against Doctors, Judicial Department of Mar del Plata (1956-1970

Expertise médicale et discours scientifique dans les procès contre les médecins pour avortement. Juridiction du Département de Mar del Plata (1956-1970)

\section{Agustina Cepeda}

\section{OpenEdition}

Journals

Edición electrónica

URL: http://journals.openedition.org/rhj/1188

DOI: $10.4000 /$ rhj. 1188

ISSN: 0719-4153

Editor

ACTO Editores Ltda

Referencia electrónica

Agustina Cepeda, «Pericia médica y discurso científico en los juicios a médicos por aborto.

Departamento Judicial de Mar del Plata (1956-1970) », Revista Historia y Justicia [En línea], 10 | 2018, Publicado el 02 mayo 2018, consultado el 18 marzo 2020. URL : http://journals.openedition.org/rhj/ 1188 ; DOI : https://doi.org/10.4000/rhj.1188 


\title{
PERICIA MÉDICA Y DISCURSO CIENTÍFICO EN LOS JUICIOS A MÉDICOS POR ABORTO. Departamento Judicial DE MAR DEL PLATA (1956-1970)
}

\author{
Agustina CEPEDA (*)
}

\begin{abstract}
Se analizan los procesos penales por maniobras abortivas entablados contra médicos obstetras del Departamento Judicial de Mar del Plata (1956-1970). Exploraré, en el expediente judicial, el discurso científico-médico y la función de los peritos. Este discurso aparece en estos casos bajo dos enunciados distintos: como peritaje legal y como declaración testimonial de los acusados. Estas reflexiones buscan contribuir al estudio de las relaciones establecidas entre los saberes producidos por el campo médico científico sobre la reproducción y las concepciones jurídico-legales de aborto, derecho(s) y vida humana.
\end{abstract}

Palabras Clave: justicia penal, Argentina, 1956-1970, aborto, medicina legal

Medical Expertise and Scientific Discourse in Abortion Trials against Doctors, Judicial Department of Mar del Plata (1956-1970)

In this article, I analyse the criminal proceedings for abortive manoeuvres against obstetricians in the Judicial Department of Mar del Plata (1956-1970).I will focus on the use of scientific-medical discourse and the role of experts in judicial files. This discourse appears in these cases in two different forms: in the statement of expert witnesses, and inthe testimony of the defendants. These reflections aims to contribute to thestudy of the relationship between scientific knowledge on reproduction and legal conceptions of abortion, rights, and human life..

Keywords: criminal justice, Argentina, 1956-1970, abortion, forensic medicine
Expertise médicale et discours scientifique dans les procès contre les médecins pour avortement. Juridiction du Département de Mar del Plata (1956-1970)

Cet article analyse les procédures criminelles contre des obstétriciens pour manœuvres visant à provoquer un avortement dans la juridiction du Département de Mar del Plata (1956-1970). Il s'agit d'examiner le discours et le rôle des experts dans les dossiers judiciaires. Ce discours apparait, dans les cas judiciaires, sous deux formes différentes: dans la déposition des experts et dans les déclarations des accusés. Ces réflexions ont pour objectif de contribuer à l'étude des relations entre le savoir scientifique sur la reproduction et les conceptions juridiques de l'avortement, des droits et de la vie humaine.

Mots clé: justice criminelle, Argentine, 1956-1970, avortement, médecine légale

Recibido: 26 de enero de 2018 / Aceptado: 12 de abril de 2018

(*) Licenciada en Historia. Doctoranda en Ciencias Sociales, IDES, Universidad Nacional de Mar del Plata. Docente, Facultad de Humanidades y Facultad de Ciencias de la Salud y Trabajo Social, Universidad Nacional de Mar del Plata. Integrante del Grupo de Estudios sobre Familia, Género y Subjetividades, Centro de Estudios Sociales y Políticos, CESP, Universidad Nacional de Mar del Plata, Argentina. agustinacepeda@yahoo.com.ar 


\title{
Pericia médica y discurso científico en los juicios a médicos por aborto. Departamento Judicial de Mar del Plata (1956-1970)
}

\author{
Agustina CEPEDA
}

\section{Introducción}

En la Argentina los estudios históricos sobre el aborto ilegal para el siglo $\mathrm{XX}^{1}$ han reparado tangencialmente en el universo de las prácticas judiciales ${ }^{2}$. La interrupción de la gestación fue analizada desde los discursos de médicos, políticos y expertos en el marco de los debates sobre la natalidad y de natalidad para la primera mitad del siglo. Frente a la dificultad empírica de trabajar con datos epidemiológicos (debido a la ausencia de registros estadísticos), las investigaciones históricas centraron su atención en los discursos punitivos, morales y religiosos de diversos actores sociales, contrastándolos con las acciones de los feminismos nativos y sus representantes ${ }^{3}$.

Desde otras propuestas teóricas-metodológicas, la historia de las prácticas del control de la natalidad relatadas por las propias mujeres fueron incorporadas a la agenda de pesquisas con la clara intención de conocer a partir de dichas narrativas, la autonomía reproductiva, el uso de anticonceptivos y la práctica del aborto como método regulatorio de la natalidad ${ }^{4}$.

\footnotetext{
1 Esta investigación forma parte de los relevamientos documentales de mi tesis doctoral "Cuerpos en delito. Aborto, mujeres y justicia en Argentina. Departamento Judicial de Mar del Plata 1956-1995" y del Proyecto PICT2014-3275, "Ciencias médicas y género. Campo médico y producción de saberes sobre hormonas sexuadas en Argentina en la segunda mitad del siglo XX". Investigador Principal Cecilia Rustoyburu. Una versión preliminar de este trabajo fue presentado en el I Workshop "Fuentes judiciales, estudios sociales y género", Universidad Nacional de Quilmes, Agosto 2017.

2 El aborto es ilegal en Argentina tal como lo plantea el artículo 86 del Código Penal. Desde 1921 el aborto no punible solo puede ser realizado por un médico diplomado cuando corre riesgo de vida la mujer o cuando el embarazo afecta a su salud, también cuando el embarazo es producto de una violación a una mujer idiota o demente.

${ }^{3}$ Nari, Marcela, Políticas de maternidad y maternalismo político. Buenos Aires, 1890-1940, Biblos, Buenos Aires, 2004, p. 319.

${ }^{4}$ Lechner, María Paula, "Matrimonio eugenésico, sexualidad y doble moral. Buenos Aires 1930-1960" en Cepeda, Agustina \& Rustoyburu, Cecilia (comp.), De las hormonas sexuadas al viagra. Ciencia, medicina y sexualidad en Argentina y Brasil, Eudem, Mar del Plata, 2014, p. 301; Felliti, Karina, "El placer de elegir. Anticoncepción y liberalización sexual en la década del sesenta" en Gil Lozano, Fernanda \& Pita Valeria \& Ini María, Gabriela (dirs.). Historia de las
} 
Específicamente en el campo de la historia social de la justicia, los trabajos con expedientes penales sobre aborto exploraron en detalle las realidades del siglo XIX. En esas investigaciones pioneras, las cuestiones del honor, la maternidad, el infanticidio y el estatus jurídico de las mujeres frente a la ley se convirtieron en objetos de análisis ${ }^{5}$. Sabemos muy poco sobre los procesos penales por maniobras abortivas para el siglo XX levantados contra mujeres y contra profesionales de la salud 6 .

¿Qué se puede conocer a partir del trabajo con expedientes sobre la cultura legal de un sistema jurídico y sobre una práctica clandestina como el aborto? En esta investigación volvemos al expediente como fuente primaria $^{7}$, en el marco de los procesos judiciales por maniobras abortivas a médicos y parteras en el Departamento Judicial de Mar del Plata, al sur de la Provincia de Buenos Aires, entre su fundación en el año 1956 y 19708.

En el expediente judicial, estudiaré los canales de legitimación de la praxis de las instituciones jurídicas, a partir de la exploración de los lenguajes involucrados en ese proceso de legitimación. La forma de abordar la cultura jurídica y las prácticas penales alrededor de un tipo delictivo específico, en nuestro caso la interrupción ilegal de la gestación, es preguntándose acerca de quiénes eran los operadores jurídicos, cómo se conformaron las redes de la familia judicial, cómo fueron las interacciones cotidianas al interior de las Cámaras y de los Tribunales Superiores, y qué tipo de relaciones existían entre las instrucciones, la policía, la política y los

mujeres en Argentina, Tomo II, Siglo XX, Taurus, Buenos Aires, 2000 Nari, M., Politicas de maternidad y maternalismo político, 2004, Op. Cit.

${ }^{5}$ Dalla Corte Caballero, Gabriela, "Control de la procreación y generización del Derecho Penal en la Argentina decimonónica: un estudio de caso", Arenal. Revista de Historia de las Mujeres, vol. 3, n³, 1996, p. 279-302; Guy, Donna, White Slavery and Mothers Alive and Death. The Troubled Meeting of Sex, Gender, Public Health, and Progress in Latin America, University of Nebraska Press, Lincoln, 2000, p. 216; Rugiero, Karin "Not Guilty: Abortion and Infanticide in Nineteenth-Century Argentina" en Aguirre, Carlos \& Buffington, Robert (eds.), Reconstructing Criminality in Latin America, Scholarly Resources, Wilmington, Delaware, 2000, p. 149-166; Rugiero, Karin, Modernity in the Flesh: Medicine, Law and Society in turn-of-the-Century Argentina, Stanford University Press, Stanford, 2004, p. 244; Calandria, Sol, "Madres criminales: aportes sobre el infanticidio y la criminalidad femenina bonaerense en clave sociodemográfica", Revista Población y Sociedad, vol. 24, n², 2017, p. 5-31.

${ }^{6}$ Cepeda, Agustina, "Historia de una práctica clandestina. Justicia penal y aborto en Mar del Plata en las décadas de 1960 y 1970”, Revista de Trabajo Social Plaza Pública, año 7, n¹1, 2014, p. 135-154.

7 Barreneche, Osvaldo, "Del 'expediente judicial' a las disposiciones 'estrictamente secretas y confidenciales'. Itinerarios historiográficos sobre los archivos y fuentes históricas de la justicia y las instituciones de seguridad y del castigo en la Argentina", Revista Electrónica de Fuentes y Archivos del Centro de Estudios Históricos Prof. Carlos S. A. Segreti, año $6, n^{\circ}$ 6, 2015, p. 13-25.

${ }^{8} \mathrm{El}$ período encierra la unidad de sentido y el recorte de la investigación donde se inscriben estas reflexiones. En 1956 se crea el Departamento Judicial de Mar del Plata, que exigió el nombramiento de nuevas autoridades y administradores de justicia que ya no dependerían del Departamento Judicial de Dolores. Utilizamos ese punto de inicio que coincide además con un nuevo escenario jurídico posperonista. El cierre es hacia fines de los años setenta cuando se modifican las discusiones en torno del estatus del embrión y de las capacidades tecnológicas de su visibilización que afectan el campo de la medicina legal en relación a los debates sobre aborto terapéutico. 
peritos. Esta aproximación hace del expediente judicial una herramienta, y ella requiere un análisis de los contenidos que enmarcan el objeto o los objetos de referencia (las prácticas médicas legales o ilegales, en relación a la interrupción de la gestación y la viabilidad del embrión desde la concepción como principio irreductible); los recursos discursivos (las construcciones semánticas sobre los contenidos), y los elementos extra-discursivos de los objetos que convoca. Es preciso identificar estos componentes, para reconocer el itinerario argumental de los enunciadores (peritos, fiscales, jueces o acusados ${ }^{9}$ ), y para visualizar en su progresión narrativa la consolidación de los razonamientos que producen significados.

En esta investigación no se observaron directamente las prácticas penales, sino que éstas aparecen en el marco de las fuentes judiciales, los expedientes, que establecen un orden particular del discurso mediadas por el lenguaje. En palabras de Chartier se trata de representaciones de esas prácticas, si entendemos que las representaciones son las formas a través de las cuales las comunidades perciben y comprenden su sociedad, y por las que los individuos y los grupos dan sentido al mundo que les es propio ${ }^{10}$.

Todas las fuentes judiciales relevadas fueron causas seguidas en primera instancia contra mujeres, hombres y profesionales de la salud entre 1956-1995 del Departamento Judicial de Mar del Plata, al sur de la Provincia de Buenos Aires, y fueron entablas por maniobras abortivas. En este artículo trabajaré con un recorte temático -solo causas contra médicos- y temporal más acotado.

En algunos casos pude seguir el expediente hasta los Tribunales Superiores de la Provincia de Buenos Aires. También revisé los índices de sentencias definitivas de primera instancia, y los índices de inicio de causa para todo el periodo ${ }^{11}$. Como las series de algunos años quedaban incompletas, revisé los fallos y las sentencias de la Suprema Corte de Justicia de la Provincia de Buenos Aires, sobre el delito de aborto desde 1940 hasta 1995. También rastreé los motivos por los que una causa de aborto podía llegar a la Corte Suprema de Justicia de la Nación Argentina.

\footnotetext{
${ }_{9}^{9}$ Meccia Ernesto, "Imaginación jurídica y experiencias trans. Una aplicación del método de análisis sociológico del discurso" en Barrancos, Dora \& Guy, Donna \& Valobra, Adriana (comp.), Moralidades y comportamientos sexuales. Argentina (1880-2011), Biblos, Buenos Aires, 2014, p. 412.

${ }^{10}$ Chartier, Roger, Escribir las prácticas. Foucault, De Certean y Marin, Manantial, Buenos Aires, 2006, p. 128; Steadman Jones, Gareth, "La postura determinista: algunos obstáculos para el futuro desarrollo de la aproximación lingüística a la historia en los años '90", Entrepasados, n’14, 1998, p. 119-13.

${ }^{11}$ El primer trabajo de archivo lo realicé con la colección de los fallos de las Cortes de Justicia Provinciales y ahí es donde se confirmó esa primera idea: en Argentina era más fácil escapar al proceso judicial por medio de un aborto clandestino que acceder a un aborto no punible. Es también en este trabajo de campo inicial con las fuentes judiciales donde exploré que la Provincia de Buenos Aires y la Capital Federal eran los espacios geopolíticos y administrativos que más procesos tenían. Pero aún me faltaba poder analizar un recorte más localizado, donde fuera posible estudiar los expedientes de los procesos penales y no sólo el resumen de la causa. Eso fue posible a partir del trabajo en el Archivo del Departamento Judicial de Mar del Plata.
} 
Ensayé la mirada sobre estas fuentes que proponen algunas investigaciones de la antropología jurídica. Estas aproximaciones me permitieron problematizar la justicia como una práctica ritualizada, e imprimir dinamismo al análisis del pasado, el que emprendí desde el reconocimiento del lugar de los agentes históricos en el proceso de construcción de verdades jurídicas en torno del aborto.

Analicé un total de 130 causas penales sobre maniobras abortivas, de primera instancia para el Departamento Judicial de Mar del Plata desde 1956 hasta 1995. De éstas, sólo pude acceder a 30 expedientes completos. En este trabajo de campo recuperé un abanico de discusiones alrededor de los procesos penales por maniobras abortivas: quiénes eran las mujeres procesadas y acusadas por el delito, cómo eran esos procesos penales, quiénes intervenían, qué nociones circulaban en torno de la moral, la honra, la cuestión sexual y reproductiva al interior de la justicia provincial ${ }^{12}$. El trabajo con los expedientes me permitió pensar el delito en distintas instancias del sistema judicial, las retóricas de los abogados y fiscales para exculpar o responsabilizar a las mujeres de interrupción ilegal de la gestación, y analizar las interpretaciones de los operadores jurídicos. Estudiar procesos asociados al sistema del derecho y a la justicia sobre una práctica clandestina y generizada supone intentar cuestionar algunos límites interpretativos. Reconociendo que el derecho penal es una ciencia de la diferencia sexual heteronormativa, el desafío de esta investigación es que este argumento insoslayable no resuene como única base de mis explicaciones del por qué y cómo se prohíbe el aborto en Argentina.

En esta oportunidad exploro una línea de preguntas, que surge en los procesos penales incoados contra los profesionales acusados de aborto, que tiene que ver con cómo pensar, al interior del expediente judicial, el discurso científico-médico y la función de los peritos.

Analizaré los debates sobre la comprobación material del ilícito -las maniobras abortivasa partir del lugar del peritaje legista en los procesos penales contra médicos. Seleccioné dos casos contra médicos ginecólogos en los que se discute quién detenta los criterios de legítima indicación de la interrupción terapéutica de la gestación. Los debates sobre qué prácticas son legítimas y cuáles no, en función de los actores, las circunstancias y los hechos, devienen el núcleo del litigio. La medicina legal, encarnada en la narrativa del peritaje, protegió fuertemente el sentido de las prácticas médicas, según un principio que no tiene que ver necesariamente con la vida desde el momento de la concepción, sino con el poder de definir cuándo una vida vale y cuándo no.

También exploro la particularidad de la convivencia de discursos del mismo género entre peritos y acusados, y cómo la alegoría retórica se utiliza en el proceso de construcción de la

12 Cepeda, A., "Historia de una práctica clandestina", Op. Cit., p.135-154. 
verdad jurídica en las causas contra médicos ${ }^{13}$. Estas reflexiones, ancladas en la investigación de campo, contribuirán a estudiar, en el marco de las dinámicas de los procesos penales, qué tipo de relaciones se establecieron entre, por un lado, los saberes producidos por el campo médico científico sobre la reproducción y, por otro, las concepciones jurídico-legales de aborto, derecho(s) y vida humana a través del papel del peritaje médico-legal. Se interroga la participación de la ciencia médica en la justicia penal, específicamente en los procesos sobre maniobras abortivas.

El artículo se organiza en dos apartados. En el primero se presentan brevemente las particularidades normativas de la medicina legal en la Provincia de Buenos Aires, las definiciones técnicas sobre aborto ilegal y las técnicas de la pericia. Se definen dos formas de clasificar los argumentos del discurso científico (según los recursos discursivos que se desarrollan): el repertorio empiricista y el repertorio contingente, en relación a los argumentos de legítima indicación de la interrupción. En el segundo apartado se analizan dos casos de procesos penales contra médicos obstetras, acusados de aborto, y las discrepancias entre los alegatos de la defensa de éstos, sus declaraciones testimoniales y el discurso de los peritos legistas. En el primero de ellos se confrontan los discursos en torno a los procedimientos técnicos de interrupción terapéutica del embarazo, según la técnica de Boero; en el segundo caso se analiza el debate sobre las indicaciones terapéuticas de aborto legal.

\section{Medicina legal, aborto y discurso científico}

La historia de la ciencia médica legal o de la medicina legal en los procesos judiciales fue estudiada para el siglo XIX especialmente desde los discursos sobre psiquiatría, eugenesia y locura ${ }^{14}$. Este tipo de saber experto nació al calor de la criminología positivista y ensayó un discurso criminal a partir de la indagación del cuerpo. Esa criminología decimonónica afirmó el papel central de la pericia médica en las decisiones judiciales mientras desarrollaba los dispositivos de medicalización de la sociedad ${ }^{15}$.

La historiografía ha estudiado, desde distintas aristas ${ }^{16}$, la publicación más importante de los primeras cuatro décadas del siglo XX, en relación al campo de la medicina legal: la Revista

\footnotetext{
${ }^{13}$ Fairclough, Norman, Analyzing Discourse: Textual Analysis for Social Research, Routledge, London, 2003, p. 288.

${ }^{14}$ Landaburu, Argentino, "Los últimos cincuenta años de la medicina legal en Argentina", Historia General de la Medicina Argentina, Dirección General de Publicaciones, Córdoba, 1980, T. II, p. 54-62.

${ }^{15}$ Salvatore, Ricardo, "Sobre el surgimiento del Estado Médico legal en la Argentina, (1890-1940)", Estudios Sociales, vol. XI, n'20, 2001, p. 81-114.

${ }^{16}$ El discurso médico legal también fue revisitado en el ámbito jurídico en el marco de los estudios sobre la psiquiatría, la infancia peligrosa, las mujeres. Véase: Cesano, José Daniel, Criminalidad y discurso médico-legal (Córdoba, 1916-1938), Editorial Brujas, Córdoba, 2013, p.143; Piazzi, Carolina (coord.), Modos de hacer justicia. Agentes, normas y prácticas. Buenos Aires, Tucumán y Santa Fe durante el siglo XIX, Prohistoria, Rosario, 2011, p. 150; Castells, Florencia, "Las mujeres histéricas en la configuración del discurso médico legal (1898-1913)", IX Jornadas de Sociología de la
} 
de Psiquiatría y Criminología, que es la continuación de la Revista de Criminología, Psiquiatría y Medicina Legal (1913-1934) y de la Archivos de Psiquiatría, Criminología, Medicina legal y Ciencias Afines (1902-1913) ${ }^{17}$; pero no existen trabajos que crucen esta publicación y la interrupción ilegal de la gestación.

Una primera exploración sobre el lugar de la discusión médico-legal en los procesos de aborto surgió desde un caso penal que informó sobre las formas médico-tecnológicas de test de embarazo (para comprobar el cuerpo del delito se debe demostrar científicamente el embarazo). A mediados del siglo XX, las formas de detección temprana del embarazo se reducían a la Hormona Gonadotropina Coriónica (HGC) en la orina ${ }^{18}$. Esa investigación me permitió plantear que las mujeres no habían sido procesadas, a pesar de que se demuestran las maniobras abortivas, porque no se había podido acreditar el embarazo.

María José Correa Gómez plantea que existe ${ }^{19}$ una historiografía que problematiza la construcción de la verdad jurídica, y analiza "los procesos de adquisición de legitimidad y autoridad de los agentes, espacios y objetos científicos" en el ingreso de la ciencia y medicina en el terreno judicial ${ }^{20}$. Esa historiografía analiza cómo se modernizaron los dispositivos

UNLP, 5 al 7 de diciembre de 2016, Ensenada, Argentina, Memoria Académica, http://www.memoria.fahce.unlp.edu.ar/trab eventos/ev.8836/ev.8836.pdf, consultado el 24 de agosto del 2017; Campos, Ricardo, "Los fronterizos del delito. Las relaciones entre crimen y mala vida en España y Argentina a comienzos del siglo XX" en Girón, Álvaro \& Miranda, Marisa \& Sierra, Álvaro, Cuerpo, biopolitica y control social, Editorial Siglo XXI, Buenos Aires, 2009, p. 318.

17 Salessi, Jorge, Médicos, maleantes y maricas. Higiene, criminología y homosexualidad en la construcción de la nación argentina (Buenos Aires, 1817-1914), Beatriz Viterbo, Rosario, 1995, p. 413; Ruibal, Beatriz, "Medicina legal y derecho penal a fines del siglo XIX" en Lobato, Mirta (ed.), Politica, médicos y enfermedades. Lecturas de bistoria de la salud en la Argentina, Biblos, Buenos Aires, 1996, p. 246; Scarzanella, Eugenia, Ni gringos ni indios. Inmigración, criminalidad y racismo en Argentina, 1890-1940, Universidad Nacional de Quilmes, Quilmes, 2002, p. 245; Nouzeilles, Gabriela, "Políticas médicas de la histeria. Mujeres, salud y representación en el Buenos Aires de fin de siglo", Mora. Revista del Instituto Interdisciplinario de Estudios de Género, n⿳5, 1999, p. 97-110; Mailhe, Alejandra, "El archivo de Archivos. Un latinoamericanismo eurocéntrico en la psiquiatría y la criminología de principios de siglo XX", Varia Historia, nº54, 2014, p. 655-678; Biernat, Carolina \& Ramacciotti, Karina (eds.), Historia de la salud y enfermedad. Bajo la lupa de las ciencias sociales, Biblos, Buenos Aires, 2014, p.163; Di Liscia, María Silvia \& Bohoslavsky, Ernesto (eds.), Instituciones y formas de control social en América Latina, 1840-1940, Prometeo, Buenos Aires, 2005, p. 219; Di Liscia, María Silvia, Saberes, terapias y prácticas indigenas, populares y cientificas en Argentina (1750-1910), Colección Biblioteca de Historia de América, Consejo Superior de Investigaciones Científicas, Madrid, 2003, p. 372; Di Liscia, María Silvia \& Billorou, María José, "Locura y Crimen en el discurso médico-jurídico. Argentina, Territorio Nacional De La Pampa, Ca. 1900", Anuario de Estudios Americanos, vol. 60, n², 2003, p. 581-606.

18 Cepeda, Agustina, "Au temps du Test du crapaud: Justice, avortement et politiques de population en Argentine vers la moitié du XXème siècle", Clio. Historie, Femmes et Sociétes, n 39, 2014, p. 239-254.

${ }^{19}$ Correa Gómez, María José, “ 'No siempre (las) tripas llevan pies'. Toxicología, análisis científico y condiciones procesales", Revista Historia y Justicia, no8, 2017, p. 69-96.

${ }_{20}$ Bunn, Geoffrey, A Social History of the Lie Detector, The Johns Hopkins University Press, Baltimore, 2012; Lynn, Michael et al, Truth Machine. The Contentious History of DNA Fingerprint, The University of Chicago Press, Chicago, 2008; Shapin, Steven, A Social History of Truth. Civility and Science in Seventeenth-Century England, The University of 
técnicos y tecnológicos en los procedimientos del peritaje médico legal, incorporando la observación científica, la toma de muestras, los análisis de laboratorio, el traslado de las muestras y la conservación de la escena criminal, modificando con todo ello los tiempos de resolución del crimen judicial.

En Argentina, solo en 1944 se aprueba y organiza, en el Estatuto de la Policía Federal, la función médica pericial, correspondiendo esta tarea a la División Técnica de la Dirección de Investigaciones ${ }^{21}$. Ya se había creado el Médico de Tribunales, figura que se irá tramando con el poder penal, y al cual se le adjudicarán tareas específicas en el marco de la función legal y forense; por ejemplo, su intervención en los casos de necropsia de muertes de madres con abortos sospechosos de ser provocados, y de fetos productos de abortos sospechosos.

En 1935, la ley 12. 210 de la provincia de Buenos Aires ya establecía que el peritaje médico-legal podía ser realizado únicamente por quienes tuvieran el diploma de médico legista, a pesar de que seguía vigente lo estipulado por el Código Procesal Penal de la Provincia de Buenos Aires desde 191522. En el Código de 1915 se indicaba que los peritos debían tener título referido a las ciencias, arte o "industria" específica del caso sobre el cual se solicitara intervención; si no había especialistas, o el arte no estaba reglamentado, se podía designar como perito a cualquier persona mayor de edad. A partir de 1935, se precisa que será cualquier profesional médico.

En medicina legal, una de las definiciones más usadas en torno del tema del aborto fue la de Nerio Rojas (un psiquiatra y médico legista, director de la Revista de Medicina Legal entre 1931-1961). Rojas esclarecía en 1936 las diferencias entre las definiciones de la obstetricia y los supuestos de la medicina legal sobre el aborto, en tiempos donde la detección y diagnóstico biológico del embarazo estaba en desarrollo. La importancia de dirimir entre el tiempo de gestación y el momento de la interrupción, así como de sus mecanismos, se transformó en objeto de la medicina legal.

Chicago Press, Chicago, 1994; Bates, Victoria, Sexual Forensic in Victorian and Edwardian England. Age, Crime and Consent in the Courts, Palgrave Macmillan, Basingstoke, 2016; Mohr, James, Doctors and the Law: Medical Jurisprudence in Nineteenth-Century America, Oxford University Press, New York, 1993; Charles E. Rosenberg, The Trial of the Assassin Guiteau: Psychiatry and Law in the Gilded Age, University of Chicago Press, Chicago, 1968; Clark Michael \& Crawford, Catherine (eds.), Legal Medicine in History, Cambridge University Press, Cambridge, 1994.

${ }^{21}$ Bonet, Emilio, "Disposiciones legales de importancia criminológica y psiquiátrico forense que entraron a regir durante el año 1968", Anales Internacionales de Criminología, vol. 9, 1970, p. 142-168.

${ }^{22}$ Jofré, Tomás, Nuevo Código de Procedimiento Penal de la Provincia de Buenos Aires, con prólogo y notas del autor del proyecto Dr. Tomás Jofré, V. Abelardo Editor, Librería Jurídica, Buenos Aires, 1915; Juárez García, Mario, Deficiencias del Procedimiento Penal de la Provincia de Buenos Aires, Impr. Mercatali, Buenos Aires, 1927; Código de Procedimiento Penal de la Provincia De Buenos Aires / Precedido de una Introducción por Tomás Jofré, Imprenta de Félix Lajouane, Buenos Aires, 1955; Lozano Baudón, Guillermo, Código de Procedimiento Penal de la Provincia de Buenos Aires y Leyes Complementarias Jurisprudencia, Doctrina y Comentarios, Librería Jurídica, La Plata, 1971; Hortel, Eduardo Carlos, Código de Procedimiento Penal de la Provincia de Buenos Aires, Editorial Universidad, Buenos Aires, 1986. 


\begin{abstract}
"En obstetricia se considera como aborto la expulsión del producto de la concepción hasta el final del sexto mes del embarazo. La expulsión durante los tres últimos meses, se denomina parto prematuro. Esta diferencia está fundada en la viabilidad del feto, que existe desde los 180 días de vida intrauterina; pero en ambas formas carece de importancia la causa -patológica, criminal o terapéutica- de la expulsión fetal. Este concepto, pues, no tiene aplicación médico-legal, porque aquí carece de valor la simple distinción cronológica. (...) Otra cuestión vinculada a este acto criminal es la muerte del producto de la concepción. Es lo que suele denominarse 'feticidio' ",23.
\end{abstract}

Unos años más tarde, y a raíz de un informe pericial sobre un aborto terapéutico, Roberto Ciafardo, Director del Cuerpo Médico de la Policía de la Plata, narraba las dificultades técnicas de detectar el embarazo y, asimismo, discutir sobre las maniobras abortivas. Al momento de su escrito, en 1935, el autor no conocía lo que sería el método más famoso y certero de diagnóstico precoz del embarazo, el test del sapo, creado por el bioquímico argentino Carlos Galli Mainini24. Lo interesante del caso discutido por Ciafardo es que la pareja que solicitaba un asesoramiento para una interrupción legal del embarazo, ocultaba en realidad un adulterio de la mujer embarazada. La autorización fue desechada.

Rojas y Ciafardo establecieron los criterios del peritaje en los casos de aborto (que son los que configuran el delito) y que rigieron hasta 1970, cuando la incorporación de nuevas técnicas de laboratorio, y de imágenes, habilitaron otro tipo de discusiones en torno de la viabilidad del embrión y del diagnóstico del embarazo. Los criterios de los nombrados legistas eran: (a) comprobar que la mujer estaba o había estado embarazada; (b) comprobar que las maniobras abortivas (que incluyen la expulsión del feto por distintos mecanismos) se hubieran realizado para matar el feto; y (c) que el feto muriera a causa de esas maniobras mecánicas, químicas o farmacológicas.

En caso de aborto terapéutico (cuando la mujer era idiota o demente, o cuando el embarazo era riesgoso para la salud de la mujer), los médicos diplomados estaban autorizados a interrumpir el embarazo. ¿Cuándo existía legitima indicación de interrupción de la gestación? ¿Podía un aborto terapéutico ser entendido como criminal (o al revés), de acuerdo a las pericias y a lo estipulado por la ley?

En mis investigaciones he intentado reconstruir, desde el trabajo con expedientes judiciales de procesos penales sobre aborto, los sentidos que los distintos actores que participan del hecho jurídico le otorgan a la práctica, para comprender dónde radica la

\footnotetext{
${ }^{23}$ Rojas Nerio, "Concepto Médico Legal del aborto", Revista Médica Hondureña, año I, 1931, p. 59.

${ }^{24}$ Del Campo Haschen, Carlos, "Posibilidad de la valoración cuantitativa de la reacción de Galli Mainini en sangre y orina", Sociedad de Obstetricia y Ginecología de Buenos Aires. Décima Reunión Cientifica ordinaria, 17 de octubre de 1957, p. 469- 477; Galli Mainini, Roberto, "Reacción diagnóstica del embarazo en la que se usa un sapo macho como animal reactivo", La semana médica, Anuario 1946-1947, p. 259-260.
} 


\section{Revista Historia y Justicia}

ISSN 0719-4153 revista.historiayjusticia.org

N¹0 - Santiago de Chile, abril 2018, p. 77-103

vitalidad de los argumentos en torno de la prohibición ${ }^{25}$. Explorar los expedientes, más allá de las retóricas específicas del género judicial y más allá del ritual penal, permite exponer los puntos de fuga y las contradicciones argumentales ancladas en los principios científicos de la defensa de la vida. La vida desde el momento de la concepción, primer y último argumento de la penalización de la interrupción voluntaria de la gestación, es presentada como un principio científico, que sirve de base para el razonamiento sobre la punición de la práctica en los regímenes legales prohibicionistas, como el argentino. Este discurso establece la viabilidad del embrión como principio irreductible.

Mi idea es explicar que este enunciado responde a un proceso social de negociaciones, situadas en un tiempo y un espacio, donde los campos trans-científicos están atravesados, en palabras de Karin Knorr Cetina, por relaciones sociales en las cuáles los científicos sitúan su producción de conocimiento. La lectura científica sobre el aborto convierte a la noción de vida en un principio ético, que termina orientando las acciones médico-legales y éstas, definiendo a su vez los procesos judiciales ${ }^{26}$.

Michel Foucault plantea que el estatuto del médico comporta criterios de competencia y de saber en el marco de un sistema de diferenciación y de relaciones -reparto de las atribuciones, subordinación jerárquica, complementariedad funcional, demanda, transmisión e intercambio de informaciones- con otros individuos u otros grupos que poseen su propio estatuto (con el poder político y sus representantes, con el poder judicial, con diferentes cuerpos profesionales, con las agrupaciones religiosas). El hospital, los consultorios privados y el campo científico encuentran cierta importancia al constituirse en los ámbitos institucionales donde el médico construye, legitima y aplica su discurso. En el escenario penal, esos saberes forman parte de los canales que auxilian la búsqueda de la verdad jurídica, eliminando o comprobando sospechas indíciales y refutando testimonios, según las pruebas que configuran el delito.

En esta investigación, mi foco de análisis serán, por un lado, los procesos penales seguidos contra médicos acusados de maniobras abortivas, y, por otro, los debates del género científico-médico-experto sobre la comprobación material del ilícito entre peritos y acusados. Esta confrontación permite observar cómo los mismos principios éticos y médicos sobre la vida y la preservación de la capacidad reproductiva de las mujeres pueden ser invocados en distintos contextos, y cómo desnudan, a partir de éstos, la trama de interpretaciones a su alrededor.

Tal como plantean Gilbert y Mulkay, el discurso científico utiliza dos repertorios de argumentos que difieren entre sí, y que son esgrimidos de forma sistemática en distintos

${ }^{25}$ Cepeda, A., "Au temps du test du crapaud”, Op. Cit., p. 239-254.

${ }^{26}$ Knorr Cetina, Karin, "Laboratory Studies: The Cultural Approach to the Study of Science" en Jasanoff, Sheila et al (eds.), Handbook of Science and Technology Studies, Sage, London, 1995. 
momentos ${ }^{27}$. En situaciones formales se invoca un repertorio empiricista, donde el conocimiento científico es una consecuencia directa de la comprobación objetiva y experimental, y donde los hechos científicos hablan por sí mismos, revelando el mundo natural. Estos autores plantean que, en contextos informales, al repertorio empiricista se agrega el repertorio contingente, que es utilizado para explicar el error argumental, dentro del campo invocado, a partir de la mala interpretación de un procedimiento. Los motivos de la "mala interpretación" se remiten a cuestiones de índole personal acerca de quién lleva la investigación o la práctica a cabo. En este estilo argumental, las descripciones se construyen de modo tal que se revela la interpretación de los datos y hechos de la ciencia que cuestionan la idea de verdad científica.

En los procesos penales por aborto levantados contra médicos, una de las estrategias de los abogados defensores fue encuadrar la práctica del acusado dentro de la interrupción terapéutica de la gestación.

En las polémicas médicas sobre el aborto terapéutico y sus indicaciones, existen tres cuestiones a evaluar frente a la decisión del especialista sobre la interrupción. En primer lugar, el método terapéutico (obstétrico, quirúrgico, hormonal o químico); en segundo lugar, la enfermedad o el motivo que justifica la intervención; y finalmente, los métodos de diagnóstico de la viabilidad fetal y de la compatibilidad feto-materna. Los peritos del periodo de investigación estudiado aquí debieron evaluar estos criterios sobre una práctica ya realizada, con pocas capacidades tecnológicas y muchas incertidumbres sobre los modos químicos de diagnóstico del embarazo y de detección de embarazo post aborto.

¿En qué elementos se basaron las pericias para responsabilizar o no a los médicos por aborto ilegal, cuando estos argumentaron y defendieron la legitimidad de su intervención? Veamos dos casos.

\section{Caso I. El debate por el procedimiento médico de interrupción de la gestación: la técnica de Boero y los saberes expertos}

En 1967, un médico inyectó formol en la cavidad uterina de una mujer, para provocar un aborto, empleando la llamada "técnica de Boero", que para esos años había caído en desuso $^{28}$. Mientras la mujer era internada en estado grave, el médico fue llevado a declarar. En su indagatoria, él confesó haber realizado la técnica de Boero para lograr la expulsión de un feto muerto. El médico Peralta Ramos, que había atendido a la mujer en la guardia del Hospital, planteaba que la técnica de Boero no lograba la expulsión de un feto muerto sino

\footnotetext{
${ }^{27}$ Gilbert, Nigel \& Mulkay, Michael, Opening Pandora's box. A sociological analysis of scientists' discourse, Cambridge University Press, Cambridge, 1984, p. 202.

28 Archivo del Departamento Judicial de Mar del Plata (ADJMDP), Índice de Causas Penales (ICP), Causa $\mathrm{n}^{\circ} 6634,1969$.
} 
que estaba indicada para interrumpir una gestación, y luego lograr la expulsión. El médico de policía, por su parte, acreditaba en su informe que "las dos heridas puntiformes que exhibía la paciente en su región pubiana podían corresponder a maniobras abortivas por instilación de sustancias químicas a tal efecto", es decir, se corroboraba la aplicación de la técnica de Boero.

¿Qué era está técnica? En 1935, el Doctor Boero comunica su método de interrupción de la gestación terapéutica del embarazo ${ }^{29}$. Luego de haber conocido el método de Aburel, de inducción o adelantamiento del parto por inyección intramiótica de suero salino hipertónico, Boero presenta su método, que consistía en la punción abdominal del huevo con una inyección de formol al 40\%, aplicando un centímetro cúbico menos que el del mes de gestación del embarazo a interrumpir. El objetivo del método era "imitar a la naturaleza produciendo la muerte y retención del huevo durante cierto tiempo, el necesario para 'levantar el estado general de la enferma' y luego proceder a su expulsión en bloque" 30 .

Revisemos brevemente el debate sobre la técnica de Boero, para comprender los términos de la discusión en el caso de A. S. En 1941, el ginecólogo Guiroy, miembro de la Sociedad de Obstetricia y Ginecología de Buenos Aires, en el ateneo de debate sobre la eficacia del método de Boero, advirtió que:

“(...) Se nos presentan casos de casuística sobre embarazos cuya edad se calcula en cinco meses y medio, y yo me pregunto si es posible tener mucha pretensión de exactitud al ofrecer la edad, por ser muy difícil el diagnóstico entre los cinco y seis meses, en que entramos dentro de la viabilidad del feto y en un asunto que es del resorte de la medicina legal. ¿Esta autorizado el médico a matar un feto de seis meses o de cinco meses y medio deliberadamente? El distinguir es particularmente difícil, sino imposible. Este es el criterio que deseo dejar sentado, para manifestar no mi desacuerdo con el método de Boero, pero sí sobre su utilización, que reputo excesiva y peligrosa y hasta si se quiere pasible de sanción, ya que el médico invade terrenos que le están vedados (...) ${ }^{\text {’31. }}$.

Boero, presente en el mismo ateneo médico de discusión, respondió a la intervención del Doctor Guiroy y a la acusación de "formolizadores":

\footnotetext{
${ }^{29}$ El método fue inventado por el Doctor en ginecología y obstetricia Enrique Boero. Presidente de la Sociedad de Obstetricia y Ginecología de Buenos Aires en 1923/24. Boero había sido Jefe de las maternidades más reconocidas de la ciudad de Buenos Aires, recibió premios internacionales por sus investigaciones. Desde 1935 inició sus publicaciones sobre ensayos médicos para interrumpir embarazos de riesgo antes de la "viabilidad fetal".

${ }^{30}$ Berdeal Avila, David, "El aborto terapéutico en la mola hidatiforme. Aplicación del método del Profesor Boero", Primeras reuniones extraordinarias de la Asociación de Médicos del Hospital Durand, Tomo II, Buenos Aires, 1942.

${ }^{31}$ Jurgens, Osvaldo \& Busch, Walter, "Interrupción del embarazo por el método del Doctor Boero", Revista de la SOGIBA, Décimo Segunda Reunión Científica Ordinaria, 30 de octubre de 1941, p. 573.
} 
"Es doloroso lo que acaba de decir el Doctor Guiroy, que el profesor Vignes de París nos pone el mote de 'formolizadores'. En primer lugar recuerdo que he presentado este método no en los diarios ni en las revistas no médicas, sino en la Academia de Medicina y que se ha debatido hasta hoy en los medios estrictamente científicos. (...) El Doctor Guiroy se refiere a otro procedimiento, que es el de Aburel, que no mata al niño. ¿No es tan pasible de igual acusación el que mata un feto como el que lo hace nacer sabiendo que no es viable? ¿Qué distinción se puede hacer? (...) Soy cristiano pero no dogmático, acepto el aborto terapéutico con indicación estricta, el Doctor Guiroy parece que no acepta esta indicación terapéutica" 32 .

El debate sobre la práctica médica de interrupción de la gestación no impugnaba al método, sino los criterios médicos de aplicación. Las indicaciones de legítima interrupción del embarazo serán el objeto de discusión, tanto en la pericia médico legal del aborto como en los argumentos de los abogados defensores de los médicos procesados.

Unos años más tarde del debate y de la presentación de los métodos de Boero y Aburel, la comunidad de obstetras reconocía que las indicaciones médicas para la interrupción terapéutica del embarazo iban desapareciendo cada vez más, y que el avance técnico en los procedimientos sumó, al clásico vaciamiento de útero, los métodos clínicos, químicos y biológicos.

La Sociedad de Ginecología de Buenos Aires, SOGIBA, reconoció como métodos legales, científicos y seguros de interrupción de la gestación, en caso de abortos terapéuticos, seis mecanismos: (a) el procedimiento de Boero, (b) el procedimiento de Aburel $^{33}$, (c) las histerectomías, (d) las esterilizaciones por ligadura de trompas (por vía vaginal y por vía abdominal), (e) los métodos salinos y (f) los métodos hormonales ${ }^{34}$.

El último médico que intervino en la causa judicial de A. S. por maniobras abortivas contempladas en el artículo 86 del Código Penal, interpretó que el método de Boero "se usaba para los casos en que la gestación estaba avanzada, inyectando 2 o 3 centímetros de solución de formol a 40\% en la cavidad amniótica valiéndose para eso de la punción del huevo a través de las cubiertas abdominales".

32 Osvaldo \& Busch, Walter, “Interrupción del embarazo por el método del Doctor Boero”, Op. Cit., p. 573.

33 Duverges, Carlos, "Nuestra experiencia con el método Aburel", Boletín de la SOGIBA, 2da. Sesión Científica Ordinaria, 8 de mayo de 1941, p. 65-75; Gavioli Ricardo, "A propósito de los procedimientos de inducción del aborto y parto prematuro por vía abdominal (métodos de Aburel y Boero)", Tema Oficial de Obstetricia, 4ta. Sesión Científica Ordinaria, julio 22 de 1943, Boletín de la Sociedad de Obstetricia y Ginecología, p. 184-189.

34 Wollenweider, Carlos, "Paz armada por el método de la punción ovular según el profesor Boero", Boletín de la Sociedad de Obstetricia y Ginecología de Buenos Aires (SOGIBA), 2da. Sesión Científica Ordinaria, mayo 13 de 1943 ; Sala, Silvio \& Palazzo, Osvaldo, "Aborto terapéutico por el método de Boero", Boletín de la SOGIBA, 1938; Rodríguez López, Mario \& Giampietro, Alberto, "Interrupción de la gravidez incompatible por el método del profesor Enrique Boero", Boletín de la SOGIBA, 2das. Jornadas Rioplatenses, 1936. 
Dos meses después de haber sido condenado, el mismo médico volvió a ser procesado judicialmente por aborto de un feto de seis meses, y por haber realizado técnicas de reanimación erradas (masaje interno de corazón), que terminaron con una hemorragia interna aguda de la mujer, causante de su muerte. A. S. declaraba en esta oportunidad que había tratado a la enferma por una intoxicación, de la cual los peritos no hallaron indicios. La pericia señaló que en el cuerpo de la mujer muerta se habían practicado maniobras abortivas "como lo prueba la existencia de lesiones puntiformes en número de cinco, en la pared abdominal, cara anterior del útero y feto producidas por una aguja de punción o trocar que después de atravesar la pared y cara anterior de útero legó a lesionar el feto".

El acusado confesó que había realizado una intervención en el tórax de la mujer, operación "que sólo conocía de forma teórica". Los médicos peritos informaron que la muerte de la mujer había ocurrido como "consecuencia de las heridas del corazón que le produjera A. S. al abrir su tórax empleando una técnica inadecuada pues la abertura debe realizarse por medio de incisión paralela al reborde costal y no perpendicular a este o paralela al borde esternal como se hizo" 35 . El médico fue condenado a tres años de prisión y a diez años de inhabilitación como cirujano.

En ambas causas se discutió cómo los médicos legistas debían probar científicamente que las prácticas clínicas descriptas por el profesional médico no eran adecuadas para sus propósitos. Los registros de las fojas del expediente muestran que la jerga, cargada de atenuación retórica ${ }^{36}$, se transforma en un campo de batalla por certificar qué especialista decía la verdad ${ }^{37}$.

A diferencia de los testimonios de los casos de las mujeres procesadas por aborto -donde el cuerpo y el relato de la mujer es examinado por los médicos legistas para confrontar la materialidad del ilícito con la declaración indagatoria-, cuando un profesional de la medicina es sentado en el banquillo de los acusados, el dispositivo médico legal se esfuerza en explicar, contrarrestar y carear, con el par profesional, la configuración del delito. En estos casos, la verdad jurídica no está anclada sólo en la sospecha, sino en los medios para la defensa de la buena ciencia médica legítima y científica, que se opone al mal uso en la práctica clínica. La

\footnotetext{
35 ADJMDP, ICP, Causa no6634, foja 50.

${ }^{36} \mathrm{La}$ atenuación retórica es el recurso que le permite al sujeto mantener su presencia en el texto de la especialidad más o menos evidente y acorde con el propósito comunicativo, la audiencia y el contexto.

${ }_{37}$ Sonia Oliver Olmo analiza los efectos retóricos específicos del discurso médico. La jerga es el nombre que reciben los lenguajes de especialidad, que quedan delimitados por tres tipos de características a) sintácticas, b) semánticas y c) pragmáticas. Siguiendo la línea de análisis propuesta por Oliver Olmo, el discurso especializado es el que realizan los profesionales de cualquier ámbito ejerciendo como tales, la especialización es la profundización en el conocimiento de un objeto, normalmente llevada a cabo en el seno de un grupo social. Oliver del Olmo, Sonia, Análisis constractivo español/ inglés de la atenuación retórica en el discurso médico. El artículo de investigación y el caso clínico. Tesis Doctoral, Departamento de Traducción y Filología, Universitat Pompeau de Fabra, 2005, p.408.
} 
atenuación retórica (el recurso que le permite al sujeto mantener su presencia en el texto de la especialidad más o menos evidente, y acorde con el propósito comunicativo, la audiencia y el contexto) transmite especulaciones, que se transforman en verdades dentro del género del discurso médico, incluso en un proceso judicial.

La impugnación de los legistas de la práctica clínica ilícita apeló al argumento contingente, ese argumento científico que desacredita el contexto y los agentes que aplican un saber científico. Ello no implicó cuestionar una técnica de supresión de la vida fetal a través de la inyección de formol.

La discusión entre los médicos peritos y el médico procesado fue sobre la pertinencia de un procedimiento clínico, su interpretación y su prescripción para una patología del embarazo. El delito del aborto, la interrupción de la gestación, la discusión sobre la viabilidad de un feto de seis meses -que en procesos a mujeres y parteras, era un agravante de la pena-, aquí aparece desdibujado. Cuando los acusados son hombres y médicos, las penas no sólo son menores, sino que el nudo del expediente es otro: el enfrentamiento entre peritos y procesados por la verdad de la ciencia y la legitimidad de la práctica.

\section{Caso II. El debate por las indicaciones de interrupción terapéutica de la gestación: en la búsqueda de la configuración legal del aborto no punible}

Paulina era una mujer soltera de 37 años que trabajaba en la fábrica La Campagnola en Mar del Plata ${ }^{38}$. Quedó embarazada de su novio Héctor y se realizó un aborto en el consultorio privado del médico ginecólogo H. T. Producto de una infección, fue denunciada por un médico que la atendió por maniobras abortivas en el Sanatorio Marítimo de la ciudad. Así comienza la historia ${ }^{39}$. Dos elementos constan sin foliar después de la carátula: (a) la ficha de antecedentes y las huellas dactilares del médico, de Paulina y su novio y (b) un pedido de excarcelación bajo fianza de 5.000 pesos para H. T. El primer folio es la denuncia que el médico del servicio de salud del Sanatorio hace en la comisaría sobre las maniobras abortivas de Paulina, relatando no sólo cómo descubrió que se había practicado un aborto, sino advirtiendo que su estado de salud era gravísimo. El expediente tiene 146 fojas y el proceso judicial se prolongó durante 7 años.

Paulina permaneció internada más de un mes a causa de la infección.

Esta historia se presenta como un ejemplo paradigmático de los procesos penales por aborto: tres procesados de distinto sexo; peritajes médicos que debatían la práctica clínica

\footnotetext{
${ }^{38}$ La Campagnola es una fábrica de Conservas de pescado y tomates de la ciudad de Mar del Plata, fundada en 1912 por inmigrantes italianos. En los años 1950 la fábrica contaba con más de 800 trabajadores, en su gran mayoría mujeres.

39 ADJMDP, ICP, Causa nº4287, 1956.
} 
del profesional acusado; jueces preocupados por los daños en la capacidad reproductiva de la mujer; una pareja pobre, trabajadora, con intenciones de matrimonio, que llevó hasta los tribunales la factura de los anillos de compromiso, para probar la promesa de futura unión. En la causa testificaron en total 14 personas, entre médicos, vecinos y procesados. Cada uno de los procesados testificó al menos tres veces. Se realizaron tres peritajes del útero de Paulina, a cargo del médico de policía local. La causa finalizó con la absolución de todos los implicados.

H. T. era un médico cirujano de 59 años y carecía de la especialidad certificada sobre partos. En 1956 fue citado a indagatoria por el delito de aborto. En su declaración informó que había sido procesado por la misma causa en 1952 y en 1953, y que había sido sobreseído ${ }^{40}$. Había dos causas más abiertas contra él, que no fueron informadas cuando se supo la historia de Paulina.

Para el fiscal, el médico intentaba colocarse en una situación favorable a fin de eludir la responsabilidad de su conducta, y lo hacía desde un relato "especialista" de su práctica médica ${ }^{41}$. Las declaraciones de los otros imputados, el certificado falso, los informes médicos y las declaraciones de los otros médicos que habían intervenido a Paulina (debido a una peritonitis que terminó con ano contra natura) en Emergencias, demostraban, para la fiscalía, que $\mathrm{H}$. T. había cometido el delito de aborto y provocado lesiones graves. El 18 de octubre de 1957 la fiscalía solicitó para el médico la pena de tres años de prisión, y la inhabilitación especial para ejercer su profesión por seis años.

El juez de la causa estaba especialmente preocupado por el estado físico de Paulina. Las condiciones de su capacidad reproductiva deterioradas agravaban la situación penal del médico. Por ello, los peritajes se orientaron no solo a comprobar qué procedimientos se utilizaron para interrumpir el embarazo, sino a detectar sus consecuencias en el cuerpo de la mujer. La fiscalía pidió que un médico de tribunales certificara el estado de Paulina y su capacidad para concebir.

El comisario que instruyó la causa solicitó al médico de policía que informara sobre si existía la "asistencia de un aborto"; si éste había sido provocado o no; la fecha probable de la interrupción; los medios empleados; y el estado en que se encontraba Paulina. El informe pericial decía:

"Que la causante se encuentra en estado de aborto.

\footnotetext{
${ }^{40}$ Fue uno de los médicos fundadores de la Sociedad de Obstetricia y Ginecología de Mar del Plata en 1959. Fundó en 1938 la sala de Primeros auxilios del Pueblo de San Manuel, Provincia de Buenos Aires. Era egresado de la UBA en 1923 con el título de médico.

41 ADJMDP, ICP, Causa nº287, 1956, foja 66.
} 


\section{Revista Historia y Justicia}

ISSN 0719-4153 revista.historiayjusticia.org

Nº10 - Santiago de Chile, abril 2018, p. 77-103

1) Se trata de un aborto provocado siendo su estado muy grave, estando en peligro la vida, presentado perforación del fondo del útero de tres centímetros aproximadamente (...)

2) La fecha es probablemente de 6 días.

3) El instrumento empleado en la producción del aborto es posiblemente una cureta por las lesiones que ha producido.

4) El estado de la paciente es muy grave. El aborto es aproximadamente de tres meses dado el tamaño del útero" ${ }^{42}$.

El abogado defensor presentó sus argumentos:

“(...) que mi defendido provocó voluntariamente el aborto es exacto. Espontánea y paladinamente lo reconoció ante instrucción y luego ante el Juzgado. No hubo en esa acción intención criminal, que es la que determina la existencia de los delitos de que se les acusa. Faltando esa intención sólo podría ser incriminado por un imprudencia que se tradujera en culpa. Tampoco hubo culpa, pues ésta es el resultado de una imprevisión, negligencia, o impericia y no hubo tales, en la acción de mi defendido. Llevó a cabo el aborto luego de revisar prolija y concienzudamente a la víctima Paulina. (...) Las declaraciones de los Dres. Quillaborda y Alonso, no niegan ni prueban en contra de lo alegado por mi defendido, respecto de la necesidad terapéutica del aborto practicado por el Dr. T. Las mismas sólo podrían tener incidencia con referencia a las lesiones que presenta Paulina. En el apartado respectivo, en consecuencia, procede a analizar las mismas, como también el informe médico de foja 3.

En resumen: de las declaraciones de Paulina y de López, sin perjuicio de las inhabilidades destacadas, no resulta que el Dr. H. T. haya procedido a efectuar el aborto sin necesidad. (...) Ayudar una mujer a ocultar su deshorna es un acto humano, limpio, y caballeresco, que a nadie afecta $(\ldots)$

No encontró médicamente, otros medios para salvaguardar la salud de su paciente. Obró así, dentro de los límites del inciso 1 del artículo 86 del Código Penal. Su conducta por tanto no es punible" 43 .

La defensa desestimaba la interpretación del agente fiscal sobre las lesiones dolosas de Paulina, y señalaba que

“(...) creo haber demostrado que H. T. realizó un aborto terapéutico y que consecuentemente, su conducta fue absolutamente lícita, de tal manera, siguiendo el razonamiento fiscal, no podrían considerarse esa lesiones como dolosas, aunque se acreditara en autos, que las mismas fueron causadas por la acción de mi defendido" 44 .

42 ADJMDP, ICP, Causa nº4287, foja 3.

43 ADJMDP, ICP, Causa n ${ }^{\circ} 4287$, foja 80-81.

44 ADJMDP, ICP, Causa nº4287, foja 78. 
Los médicos que intervinieron a Paulina, y el médico legista que había hecho el peritaje, acreditaron maniobras abortivas, pero no había indicios del uso de una sonda, que era lo que había testificado el médico. El procedimiento utilizado había sido un curetaje ${ }^{45}$.

¿Qué argumentó el abogado defensor frente a esto? ¿Cómo cuestionó las pericias de los médicos legistas?

El perito de parte había afirmado que "las lesiones en el útero fueron producidas por una sonda, dadas sus características del tipo de esas perforaciones", aunque agrega que en la sección del intestino, "no le cabe duda de que ha sido producido por un elemento cortante" 46.

"No niego que esta última circunstancia podría presumirse de las declaraciones de los otros médicos que atendieron a la enferma. Así el Dr. Peñeñory imputa las lesiones a maniobras abortivas agregando que posiblemente fueron las mismas producidas por una cureta.

El Dr. Quilliborda, con sospechosa seguridad, afirma categóricamente que 'descarta por completo que las mismas hayan sido causadas por la sonda, teniendo la seguridad de que las mismas han sido inferidas por elemento cortante'.

Considero, cuando al menos, apresuradas las opiniones de los nombrados facultativos, que debe descartarse en forma absoluta, la presunción de haber usado el Dr. H. T. la cucharita de raspar el curetaje, dado que no hubo intervención cruenta, que no era posible en este caso por tratarse de un embarazo mayor de dos meses. Si se me permite la comparación, ES ELLO TAN IMPOSIBLE COMO CORTAR CABELLO DE UNA PERSONA SANA ${ }^{47}$. Se puede curetear, si, restos embrionarios, placentarios o membranosos, con el fin de hacer una limpieza a fondo y para detener flujo hemorrágico, caso que no era el de autos, sino un embarazo hemorrágico, serio y grave" ${ }^{\mathrm{s} 8}$.

Y continúa con una disertación sobre los medios terapéuticos de interrupción del embarazo, con asombroso conocimiento, e incluyendo citas de autoridades de Fourney y Siderey, Doderlin:

“(...) La sonda empleada con fines terapéuticos, puede provocar lesiones o heridas en los órganos donde está incluida. (...) Es verdad que los profanos consideran a la sonda como un elemento o agente de uso terapéutico ofensivo que no puede provocar trastorno ni lesiones de naturaleza grave y sin embargo no es así.

$\mathrm{Si}$ bien es cierto que es un elemento de goma blando, elástico, flexible de paredes suaves, hueco por dentro y punta roma, que tiene un orificio o abertura apta para el drenaje, cuando se coloca en el interior de un órgano, como el útero, puede convertirse en un agente

\footnotetext{
${ }^{45} \mathrm{El}$ curetaje es una técnica de legrado ginecológico en el útero que se utiliza como procedimiento abortivo durante los tres primeros meses.

46 ADJMDP, ICP, Causa nº4287, foja 79.

${ }^{47}$ Las mayúsculas son textuales de la cita.

48 ADJMDP, ICP, Causa nº 4287 , foja 79.
} 
o instrumento de acción traumatizante, duro, rígido, capaz de todas las lesiones y principalmente, cuando las condiciones del purgado y otras circunstancias agudizan esa predisposición. En efecto, hueca como es, dentro de un útero hemorrágico, se llena de sangre que se coagula, transformándose en un tubo flexible y blando, en un instrumento duro, rígido y punzante. Estando en una matriz o útero grávido, aprisionada e inmóvil, provoca en este órgano, de naturaleza muscular contráctil, fuertes contracciones de frecuencia inusitada y dolorosas, cuyo final expulsado de su interior, dado que para el útero, la sonda es un cuerpo extraño, esto es lo que convierte en un instrumento capaz de las más graves lesiones, máxime cuando como en el caso de autos, se estaba en presencia de un útero grávido, traumatizado de la sonda, inmóvil, dura y rígida. El estado de gravidez importa para el útero en estado de blandura y flacidez por su estado congestivo, embebido de sangre y líquidos que lo ponen en condiciones de poca resistencia y defensa. En defensa de un instrumento como el descrito, Fournet y Siderey, en su tratado de ginecología dicen que 'en el curso de la preñez, el útero sufre transformaciones muy acentuadas. Los vasos son extremadamente distendidos, los venosos le dan al útero una apariencia esponjosa'. Doderlin, en su tratado de obstetricia dice, con respecto a las alteraciones de las mucosas uterinas, lo siguiente: 'durante la implantación del huevo y después de la misma, sobreviene en la mucosa interna una intensa constitución de nuevas formaciones. Transformaciones y formaciones de tejidos nuevos hacen al principio y desarrollo de huevo y a las condiciones de vida inherentes'. Sabido es que el útero grávido es un órgano blando, esponjoso, flácido y que a nivel donde se anida el huevo existe una zona mucho más débil, de paredes de escasa resistencia, friable, una zona verdaderamente vulnerable para la acción lesiva de un instrumento traumatizante. El útero en los primeros días, pierde su tonicidad natural, que adhiere recién a partir del tercer y cuarto mes del embarazo, que es cuando adquiere una consistencia elástica y símil contráctil.

Resumiendo, surge con evidencia que el útero grávido es sumamente vulnerable ante las acechanzas de cualquier maniobra interna o externa y ante la presencia de cualquier agente dentro de su cavidad. Si la sonda es de uso y práctica diaria médico quirúrgico, hay que insistir sobre otro punto de la mayor importancia provocado por su presencia en los órganos. Cualquiera sea el órgano donde se la coloque, es para este un cuerpo extraño, que el mismo no tolera sin una reacción tratando siempre de desembarazarse de ella, es decir, de expulsarla de su interior (...)"49.

El abogado defensor de H. T. citó tratados de ginecología de Hortman, Stern y Calantroin Ruiz para justificar que la sonda intrauterina podía producir perforación, depositando en Paulina la responsabilidad de no haber seguido las instrucciones médicas.

Paulina fue citada, después de 6 años, ya casada con el mismo novio con el que estaba cuando comenzó el proceso judicial, para un reconocimiento en el consultorio del Médico de Tribunales. Allí se constató la "integridad anatómica del útero y anexos", sugiriendo una

49 ADJMDP, ICP, Causa nº4287, foja 80. 
histerosalpintografia para ratificar el estado de las trompas de Falopio y la capacidad reproductiva de la mujer ${ }^{50}$.

H. T. terminó absuelto de la causa cuando el juez acordó con el alegato del abogado defensor de que el aborto había sido terapéutico, es decir, por necesidad. A pesar de no existir acuerdo entre peritos y profesionales sobre las huellas que los procedimientos habían dejado en el cuerpo de la mujer, el médico, que tenía antecedentes, pero que era un miembro importante de la Sociedad de Obstetricia y Ginecología de Mar del Plata, quedó libre.

Los argumentos de la defensa giraron en torno a las maniobras, que no habían sido abortivas porque no tuvieron como fin la muerte del feto, o que se correspondieron con la terapéutica de la interrupción de la gestación por riesgo de la salud de la madre.

¿Qué decía la literatura médica especializada en Argentina sobre el aborto terapéutico? Los casos más debatidos entre los médicos, que se publicaron en la Revista de la SOGIBA desde 1940 hasta la década de 1970, trataban sobre cáncer y embarazo (en estos casos, la prescripción médica se preguntaba si el cáncer/tumor aumentaba o no su sintomatología durante el embarazo como para justificar su interrupción); los embarazos ectópicos y su posibilidad de cumplimentar o no una gestación a término (dependiendo de las características particulares de la paciente); y en menor medida, la estrechez pelviana, la tuberculosis pulmonar, la sífilis, la poliomielitis, lupus, enfermedad de chagas, la epilepsia, la diabetes, el asma, las cardiopatías y las enfermedades eruptivas especialmente la rubéola ${ }^{51}$.

En los años cincuenta, para las mujeres con tuberculosis, los médicos de la SOGIBA recomendaban utilizar los métodos obstétricos (dilatación y parto), porque eran mejor tolerados que los métodos quirúrgicos. Si bien el embarazo en la mujer tuberculosa no era frecuente, a causa de la infertilidad y del aborto habitual que producía la enfermedad, las indicaciones terapéuticas para estos casos eran claras: había que interrumpir el embarazo ${ }^{52}$.

\footnotetext{
${ }^{50}$ Histerosalpintografía es un estudio de contraste para detectar el estado de las trompas de Falopio y del útero a partir de inyección de iodo e imágenes radiológicas.

${ }^{51}$ Bustos Morón, Roberto, El aborto Terapéutico en la tuberculosis pulmonar, Tesis de Facultad de Medicina, Universidad de Buenos Aires, 1917; Bello, Ramón, "La cesárea vaginal en la clínica", Segunda Jornada Rioplatense de Obstetricia y Ginecología de Buenos Aires, 1936, p. 253; Bengolea, Alberto, "La pequeña cesárea por vía vaginal en la interrupción terapéutica del embarazo", Revista de Cirmgia, 1927, vol. VI, p. 385, Boletín de la SOGIBA, 1927, p. 148; León, Juan, "Aborto terapéutico y esterilización simultánea. Valor actual de los métodos quirúrgicos por vía vaginal”, Trabajo de Adscripción a la Cátedra de Clínica Ginecológica, Facultad de Medicina, Universidad de Buenos Aires, 1941; Turenne, Antonio, "Indicaciones discutidas y técnicas nuevas de la interrupción del embarazo", Archivos uruguayos de Medicina, Cirugia y Especial, 1934, Tomo IV, n² y 3, p. 18-22.

52 "De 28 años, 6 abortos provocados, un hijo vivo. Tuberculosis pulmonar evolutiva: embarazo de 40 días. Anestesia local (novocaína al 0,50\%). Pequeña cesárea vaginal con incisión del cuello. Ligadura de la trompa izquierda con seda, según Madlener", Archivo de la Biblioteca de la Facultad de Medicina de la Universidad de Buenos Aires, Archivos de la Clínica Eliseo Cantón, Historia Médica 217, 1934, citada en León Juan (1941), p. 11. La técnica de Madlener es la ligadura de trompas por vagina.
} 
Una década después en la publicación de la SOGIBA, los médicos presentaban los resultados de las investigaciones sobre el descubrimiento de los "antimicrobianos tuberculostáticos" para el tratamiento de la tuberculosis genitoperitoneal, y declaraban que las mujeres con la enfermedad no sólo podían llevar un embarazo a término, sino incluso superar luego del tratamiento, la esterilidad secundaria producto de la tuberculosis ${ }^{53}$.

Hacia 1960, la toxoplasmosis ${ }^{54}$, patología que históricamente había sido motivo de interrupción terapéutica de la gestación, es contraindicada tanto para el aborto terapéutico como para el embarazo ectópico (que demostró, con el transcurrir de las décadas, altos índices de embarazo a término) ${ }^{55}$. También se revisaron las indicaciones para los casos de embarazos con cardiopatías. En 1971, el ginecólogo Domingo Olivares proponía que la indicación por aborto terapéutico contemplara tanto el riesgo para la salud o la vida de la madre como el nacimiento de un hijo defectuoso ${ }^{56}$. La comunidad de la SOGIBA rechazó esta propuesta.

En nuestro caso, los informes de los peritos fueron desestimados en relación a las condiciones generales de Paulina, es decir, no cuestionaron que el aborto fuera terapéutico, sino que fueron considerados respecto de las consecuencias de una práctica, que, sospechada de mala praxis, evaluaba la capacidad reproductiva de Paulina.

Paulina había querido ocultar su embarazo a su familia. H. T. testificó que ella tenía un aborto en curso y que la sonda era un medio para la interrupción terapéutica. Los peritos comprobaron el uso de la sonda, la infección de Paulina y su útero perforado, pero no podían decir nada sobre la legalidad o ilegalidad del acto.

La viabilidad del embarazo quedó atada a las narraciones del médico acusado, de los peritos de parte y del abogado defensor. El núcleo de la configuración del delito del aborto, la demostración científica del estado de embarazo, viabilidad o inviabilidad de la gestación y

\footnotetext{
53 “(...) tuberculosis pulmonar desde 1951, de reinfección, activa, desarrolladas, muy avanzada, fibrocaseosa a predominio fibrosos, tratamiento durante el embarazo actual: 126 gr. De SM, 127 g. de HIN, 300g de PAS. Embarazo actual: normal a término, parto espontáneo, alumbramiento normal, graves hemoptisis los últimos 15 días de gestación. Muerte en coma en el puerperio inmediato. Embarazo a término", Archivo de la Biblioteca de la Facultad de Medicina de Buenos Aires, Historia Clínica, Hospital de la Misericordia, 1956, Sociedad de Obstetricia y Ginecología de Buenos Aires, 1963, p. 293; Curci, Alberto et al, "Tuberculosis y embarazo. Tuberculosis congénita", Revista de la SOGIBA, Decimocuarta Sesión Científica Ordinaria, 28 de noviembre, 1963, p. 396- 416.

${ }^{54} \mathrm{La}$ toxoplasmosis es una enfermedad infecciosa ocasionada por un protozoo parásito llamado toxoplasmogondii, un parásito intracelular obligado.

55 González, Juan, "A propósito del primer embarazo simultáneo intrauterino y extrauterino de término informado en la Argentina. Revisión Bibliográfica mundial", Revista de la SOGIBA, Cuarta Sesión Científica Ordinaria, 23 de junio, p. 113-118, 1960; Gori, Roberto \& Galimberti Ana, "Embarazo tubo-abdominal extra membranoso con feto vivo", Duodécima Sesión Científica Ordinaria, 27 de octubre, Revista de la SOGIBA, 1960, p. 334-339.

56 Olivares, Domingo, "El aborto Inducido", Quinta Sesión Científica, Revista de la SOGIBA, 29 de julio, 1971, p. 158.
} 
comprobación de maniobras abortivas ilegales, quedaron resguardadas por los peritajes, que se limitaron a describir el estado de Paulina y los medios utilizados, dejando fuera de la escena penal al médico $\mathrm{H}$. T.

\section{Conclusión}

La historia judicial de la interrupción voluntaria de la gestación es la historia de una práctica generizada prohibida. En otras investigaciones analicé los procesos judiciales, prestando atención a las cuestiones del derecho penal, las mujeres y el aborto. En este artículo me centré en el discurso médico-científico que circula dentro de dos expedientes judiciales incoados contra los profesionales médicos. Reconstruí los debates sobre la comprobación material del ilícito (las maniobras abortivas), examinado el lugar del peritaje médico en los procesos penales contra ginecólogos. Esos dos casos pusieron en juego quién detentaba los criterios de legítima indicación de la interrupción terapéutica de la gestación, mostrando que el núcleo del litigio fueron las prácticas, consideradas legítimas o no, en función de los actores, las circunstancias y los hechos. La medicina legal, encarnada en la narrativa del peritaje, protegió el sentido de las prácticas médicas y su capacidad de definir cuándo una vida vale y cuándo no; y también, su sanción sobre la mala praxis médica que afecta a la capacidad reproductiva de las mujeres.

El papel de los profesionales de la salud en los juicios penales por aborto expone la voluntad paradojal de éstos frente a la justicia penal, en tanto miembros de la familia punitiva sobre el aborto, y en tanto agentes de la clandestinidad de la práctica. Los profesionales son una pieza central del proceso de control social y medicalización de la reproducción de las mujeres a partir de la prohibición/punición de la práctica del aborto. ¿Qué pasa cuando los propios profesionales son acusados de maniobras abortivas?

En este artículo expuse las estrategias que los abogados defensores desarrollaron para desvincular a los profesionales médicos/as de las acusaciones de maniobras abortivas. También exploré el papel de las pericias médicas en las causas penales por aborto que involucran prácticas clínicas de médicos/as procesados. Indagué sobre cómo estos debates se producían en el campo específico de la ginecología y la obstetricia en argentina mediante la publicación periódica de la SOGIBA.

El discurso médico-científico aparece en estos casos bajo dos enunciados distintos: como peritaje legal y como declaración testimonial de los acusados.

En el primer caso, la discusión en torno de la pertinencia de la técnica de Boero y los desacuerdos sobre las interpretaciones de los peritos y médicos consultados y el acusado fueron claras, pero no suficientes para condenar al médico que había utilizado un método casi extinto de la clínica obstétrica para fines de 1950. En el segundo caso, las estrategias del 
médico H. T. para definir como aborto terapéutico la utilización de una sonda en el cuerpo de Paulina termina encontrando en los peritajes un guiño que acredita, por una parte, el procedimiento, y por otra, un útero perforado, que nada puede decir sobre las indicaciones terapéuticas para la interrupción de la gestación.

Mi argumento es que en el periodo histórico del caso de la investigación (1956-1970) la visibilización de las discusiones por la práctica del aborto quedaron circunscriptas a las corporaciones de juristas (en el escenario de propuestas de reformas legales), y a las corporaciones médicas que discutían posicionamientos frente al aborto, dependiendo de otras discusiones mayores (población, eugenesia, anticoncepción y control de la reproducción de la mujeres). Este muro de silencio controlado rodea las discusiones sobre el aborto, y encierra la práctica en los terrenos de la aplicación de la ley como norma.

Esta confrontación del discurso médico (el de los profesionales acusados y el de los legistas) me permitió pensar en cómo los mismos principios éticos y médicos en torno a la vida y a la preservación de la capacidad reproductiva de las mujeres, pueden ser invocados en distintos contextos, y cómo desnudan a partir de éstos la trama de interpretaciones a su alrededor.

Los peritos legistas utilizaron el argumento contingente para desacreditar el ejercicio ilegal de la medicina o las maniobras abortivas en manos de los profesionales de la salud, como una mala interpretación de ese principio inalterable. Denunciaron mal uso de los procedimientos médicos de interrupción terapéutica de la gestación, vale decir, cuestionan el criterio médico acerca de cuándo es necesario interrumpir un embarazo. Este juego argumental en las intertextualidades registradas en el expediente judicial permite reestablecer la frontera acerca del acuerdo de los criterios médicos, que justifican la interrupción de la gestación sin exponer a juicio de interpretación el principio de la vida y la viabilidad. La retórica de la ciencia médica, y de la justicia penal, se enhebra de tal modo que ratifican en su accionar los sentidos de la prohibición del aborto.

\section{Fuentes}

\section{Inéditas}

Archivo del Departamento Judicial de Mar del Plata (ADJMDP), Índice de Causas Penales (ICP), -Causa n ${ }^{\circ} 4287,1956$.

-Causa no 6634, 1969.

\section{Publicadas}

Bello, Ramón, "La cesárea vaginal en la clínica", Segunda Jornada Rioplatense de Obstetricia y Ginecología de Buenos Aires, 1936, p. 253-255.

Bengolea, Alberto, "La pequeña cesárea por vía vaginal en la interrupción terapéutica del embarazo", Revista de Cirugía, 1927, vol. V, nº VI, p. 385. 


\section{Revista Historia y Justicia}

ISSN 0719-4153 revista.historiayjusticia.org

Nº10 - Santiago de Chile, abril 2018, p. 77-103

Berdeal Avila, David, "El aborto terapéutico en la mola hidatiforme. Aplicación del método del Profesor Boero", Primeras reuniones extraordinarias de la Asociación de Médicos del Hospital Durand, Tomo II, Buenos Aires, 1942, p. 197-198.

Bonet, Emilio "Disposiciones legales de importancia criminológica y psiquiátrico forense que entraron a regir durante el año 1968", Anales Internacionales de Criminología, vol. 9, 1970, p. 142-168.

Bustos Morón, Roberto, El aborto Terapéutico en la tuberculosis pulmonar, Tesis de Facultad de Medicina, Universidad de Buenos Aires, Argentina, 1917.

Código De Procedimiento Penal De La Provincia De Buenos Aires / Precedido De Una Introducción Por Tomás Jofré, Imprenta de Félix Lajouane, Buenos Aires, 1955.

Curci, Alberto et al, "Tuberculosis y embarazo. Tuberculosis congénita", Revista de la SOGIBA, Decimocuarta Sesión Científica Ordinaria, 28 de noviembre, 1963, p. 396- 416.

Del Campo Haschen, Carlos "Posibilidad de la valoración cuantitativa de la reacción de Galli Mainini en sangre y orina", Sociedad de Obstetricia y Ginecología de Buenos Aires. Décima Reunión Científica ordinaria, 17 de octubre de 1957, p. 469- 477.

Duverges, Carlos, "Nuestra experiencia con el método Aburel", Revista de la SOGIBA, 2da. Sesión Científica Ordinaria, 8 de mayo de 1941, p. 65-75.

Galli Mainini, Roberto, "Reacción diagnóstica del embarazo en la que se usa un sapo macho como animal reactivo", La semana médica, Anuario 1946-1947, p. 259-260.

Gavioli, Ricardo, "A propósito de los procedimientos de inducción del aborto y parto prematuro por vía abdominal (métodos de Aburel y Boero)", Tema Oficial de Obstetricia, cuarto Boletín de la SOGIBA, Sesión científica ordinaria, julio 22 de 1943, p. 184-189.

González, Juan, “A propósito del primer embarazo simultáneo intrauterino y extrauterino de término informado en la Argentina. Revisión Bibliográfica mundial”, Revista de la SOGIBA, Cuarta Sesión Científica Ordinaria, 23 de junio, 1960, p. 113-118.

Gori, Roberto \& Galimberti Ana, "Embarazo tubo-abdominal extramembranoso con feto vivo", Duodécima Sesión Científica ordinaria, 27 de octubre, 1960, Revista de la SOGIBA, p. 334-339.

Hortel, Eduardo Carlos, Código De Procedimiento Penal De La Provincia De Buenos Aires, Editorial Universidad, Buenos Aires, 1986.

Jofre, Tomás, Nuevo Código de Procedimiento Penal de la Provincia de Buenos Aires, con prólogo y notas del autor del proyecto Dr. Tomás Jofré, V. Abelardo Editor, Librería Jurídica, Buenos Aires, 1915.

Juárez García, Mario, Deficiencias Del Procedimiento Penal De La Provincia De Buenos Aires, Imprenta Mercatali, Buenos Aires, 1927.

Jurgens, Osvaldo \& Busch, Walter, "Interrupción del embarazo por el método del Doctor Boero" Revista de la SOGIBA, Décimo Segunda Reunión Científica Ordinaria, 30 de octubre de 1941, p. 563-573.

León, Juan, "Aborto terapéutico y esterilización simultánea. Valor actual de los métodos quirúrgicos por vía vaginal", Trabajo de Adscripción a la Cátedra de Clínica Ginecológica, Facultad de Medicina, Universidad de Buenos Aires, 1941.

Lozano Baudón, Guillermo, Código de Procedimiento Penal de la Provincia de Buenos Aires y Leyes Complementarias Jurisprudencia, Doctrina y Comentarios, Librería Jurídica, La Plata, 1971.

Mercante, Víctor, Informe Médico Legal, s. n., Buenos Aires, 1917. 
Olivares, Domingo, "El aborto Inducido", Quinta Sesión Científica, Revista de la SOGIB A, 29 de julio de 1971, p. 158-170.

Rodríguez López, Mario \& Giampietro, Alberto, "Interrupción de la gravidez incompatible por el método del profesor Enrique Boero", Revista de la SOGIBA, Segundas Jornadas Rioplatenses, 1936.

Rojas, Nerio, "Concepto Médico Legal del aborto", Revista Médica Hondureña, año I, 1931, p. 57-63.

Sala, Silvio \& Palazzo, Osvaldo, “Aborto terapéutico por el método de Boero", Boletín de la SOGIBA, 1938.

Turenne, Antonio, "Indicaciones discutidas y técnicas nuevas de la interrupción del embarazo", Archivos uruguayos de Medicina, Cirugía y Especial, 1934, Tomo IV, n² y n³, p. 18-22.

Wollenweider, Carlos, "Paz armada por el método de la punción ovular según el profesor Boero", Boletin del SOGIBA, 2da. Sesión científica ordinaria, mayo 13 de 1943, p. 238-239.

\section{Bibliografía}

Angenot, Marc, El discurso social. Los límites bistóricos de lo pensable y lo decible, Siglo XXI, Buenos Aires, 2012.

Barreneche, Osvaldo, 'Del 'expediente judicial' a las disposiciones 'estrictamente secretas y confidenciales'. Itinerarios historiográficos sobre los archivos y fuentes históricas de la justicia y las instituciones de seguridad y del castigo en la Argentina", Revista Electrónica de Fuentes y Archivos del Centro de Estudios Históricos Prof. Carlos S. A. Segreti, año 6, n 6, 2015, p. 13-25.

Bates, Victoria, Sexual Forensic in Victorian and Edwardian England. Age, Crime and Consent in the Courts, Palgrave Macmillan, Basingstoke, 2016.

Biernat, Carolina \& Ramacciotti, Karina (eds.), Historia de la salud y enfermedad. Bajo la lupa de las ciencias sociales, Biblos, Buenos Aires, 2014.

Bohoslasvsky, Ernesto \& Soprano, Germán (eds.), Un Estado con rostro bumano. Funcionarios e instituciones estatales en Argentina (desde 1880 a la actualidad), Editorial Prometeo, Buenos Aires, 2010.

Bunn, Geoffrey, A Social History of the Lie Detector, The Johns Hopkins University Press, Baltimore, 2012.

Caimari, Lila, "Los historiadores y la cuestión criminal en América latina. Notas para un estado de la cuestión" en Palma Alvarado, Daniel (comp.), Delitos, Policias y Justicia en América Latina, Ed. U. Alberto Hurtado, Santiago, 2015, p. 491-507.
Calandria, Sol, "Madres criminales: aportes sobre el infanticidio y la criminalidad femenina bonaerense en clave sociodemográfica", Revista Población y Sociedad, vol. 24, n², 2017, p.5-31.

Campos, Ricardo, "Los fronterizos del delito. Las relaciones entre crimen y mala vida en España y Argentina a comienzos del siglo XX” en Girón, Álvaro \& Miranda, Marisa \& Sierra, Álvaro, Cuerpo, biopolitica y control social, Editorial Siglo XXI, Buenos Aires, 2009.

Castells, Florencia, "Las mujeres histéricas en la configuración del discurso médico legal (18981913)", IX Jornadas de Sociología de la UNLP, 5-7 de diciembre de 2016, Ensenada, Argentina, Memoria Académica, disponible en http://www.memoria.fahce.unlp.edu.ar/trab even tos/ev.8836/ev.8836.pdf, consultado el 24 de agosto de 2017.

Cepeda, Agustina, "Au temps du test du crapaud: Justice, avortement et politiques de population en Argentine vers la moitié du XXème siècle", Clio. Historie, Femmes et Sociétes, n³9, 2014, p. 239-254.

Cepeda, Agustina, "Historia de una práctica clandestina. Justicia penal y aborto en Mar del Plata en las décadas de 1960 y 1970", Revista de Trabajo Social Plaza Pública, año 7, n¹1, 2014, p. 135-154.

Cesano, José Daniel, Criminalidad y discurso médicolegal (Córdoba, 1916-1938), Editorial Brujas, Córdoba, 2013. 
Chartier, Roger, Escribir las prácticas. Foucault, De Certeau y Marin, Manantial, Buenos Aires, 2006.

Clark, Michael \& Crawford, Catherine (eds.), Legal Medicine in History, Cambridge University Press, Cambridge, 1994.

Correa Gómez, María José, “ No siempre (las) tripas llevan pies'. Toxicología, análisis científico y condiciones procesales", Revista Historia y Justicia, n8, 2017, p. 69-96.

Dalla Corte Caballero, Gabriela, "Control de la procreación y generización del Derecho Penal en la Argentina decimonónica: un estudio de caso", Arenal. Revista de Historia de las Mujeres, vol. 3, $\mathrm{n}^{\circ} 3$, 1996, p. 279-302.

Di Liscia, María Silvia \& Billorou, María José, "Locura y crimen en el discurso Médico-jurídico. Argentina, Territorio Nacional De La Pampa, Ca. 1900", Anuario De Estudios Americanos, vol. 60, n 2, 2003, p. 581-606.

Di Liscia, María Silvia \& Bohoslavsky, Ernesto (eds.), Instituciones y formas de control social en América Latina, 1840-1940, Prometeo, Buenos Aires, 2005.

Di Liscia, María Silvia, Saberes, terapias y prácticas indigenas, populares y científicas en Argentina (17501910), Colección Biblioteca de Historia de América, Consejo Superior de Investigaciones Científicas, Madrid, 2003.

Fairclought, Norman, Analyzing Discourse: Textual Analysis for Social Research, Routledge, London, 2003.

Felliti, Karina, "El placer de elegir. Anticoncepción y liberalización sexual en la década del sesenta" en Gil Lozano, Fernanda \& Pita, Valeria \& Ini, María Gabriela (dir.), Historia de las mujeres en Argentina, tomo II, Siglo XX, Taurus, Buenos Aires, 2000, p. 154-171.

Gilbert, Nigel \& Mulkay, Michael, Opening Pandora's box. A sociological analysis of scientists' discourse, Cambridge University Press, Cambridge, 1984.

Guy, Donna, White Slavery, Mothers Alive, and Death. The Troubled Meeting of Sex, Gender, Public Health, and Progress in Latin America, University of Nebraska Press, Lincoln, 2000.
Knorr Cetina, Karin, "Laboratory Studies: The Cultural Approach to the Study of Science", en Jasanoff, Sheila et al (eds.), Handbook of Science and Technology Studies, Sage, London, 1995.

Landaburu, Argentino, "Los últimos cincuenta años de la medicina legal en Argentina" en Historia General de la Medicina Argentina, Dirección General de Publicaciones, Córdoba, 1980, T. II, p. 54-62.

Lechner, María Paula, "Matrimonio eugenésico, sexualidad y doble moral. Buenos Aires 19301960" en Cepeda, Agustina \& Rustoyburu, Cecilia (comps.), De las hormonas sexuadas al viagra. Ciencia, medicina y sexualidad en Argentina y Brasil, Eudem, Mar del Plata, 2014.

Lynn, Michael \& Cole, Simon \& McNally, Ruth \& Jordan, Kathleen, Truth Macbine. The Contentious History of DNA Fingerprint, The University of Chicago Press, Chicago, 2008.

Mailhe, Alejandra, "El archivo de Archivos. Un latinoamericanismo eurocéntrico en la psiquiatría y la criminología de principios de siglo XX", Varia Historia, no54, 2014, p. 655-678.

Meccia Ernesto, "Imaginación jurídica y experiencias trans. Una aplicación del método de análisis sociológico del discurso" en Barrancos, Dora \& Guy, Donna \& Valobra, Adriana (comps.), Moralidades y comportamientos sexuales. Argentina (1880-2011), Biblos, Buenos Aires, 2014.

Mohr, James, Doctors and the Law: Medical Jurisprudence in Nineteenth-Century America, Oxford University Press, New York, 1993.

Nari, Marcela, Políticas de maternidad y maternalismo politico. Buenos Aires, 1890-1940, Biblos, Buenos Aires, 2004.

Nouzeilles, Gabriela, "Políticas médicas de la histeria. Mujeres, salud y representación en el Buenos Aires de fin de siglo", Mora. Revista del Instituto Interdisciplinario de Estudios de Género, $\mathrm{n}^{\circ} 5$, 1999, p. 97-110.

Oliver del Olmo, Sonia, Análisis constractivo español/inglés de la atenuación retórica en el discurso médico. El artículo de investigación y el caso clínico, 
Tesis Doctoral, Departamento de Traducción y Filología, Universitat Pompeau de Fabra, España, 2005.

Piazzi, Carolina (coord.), Modos de hacer justicia. Agentes, normas y prácticas. Buenos Aires, Tucumán y Santa $\mathrm{Fe}$ durante el siglo XIX, Prohistoria, Rosario, 2011.

Rodríguez, Julia, Civilizing Argentina. Science, Medicine and the Modern State, The University of North Carolina Press, Chapel Hill, 2006.

Rosenberg, Charles, The Trial of the Assassin Guiteau: Psychiatry and Law in the Gilded Age, University of Chicago Press, Chicago, 1968.

Rugiero, Karin, "Not Guilty: Abortion and Infanticide in Nineteenth-Century Argentina" en Aguirre, Carlos \& Buffington, Robert (eds.), Reconstructing Criminality in Latin America Scholarly Resources, Wilmington, Delaware, 2000, p. 149-166.

Rugiero, Karin, Modernity in the Flesh: Medicine, Law and Society in turn-of-the-Century Argentina, Stanford University Press, Stanford, 2004.

Ruibal, Beatriz, "Medicina legal y derecho penal a fines del siglo XIX" en Lobato, Mirta (ed.) Política, médicos y enfermedades. Lecturas de historia de la salud en la Argentina, Biblos, Buenos Aires, 1996, p. 246-256.

Salessi, Jorge, Médicos, maleantes y maricas. Higiene, criminologia y homosexualidad en la construcción de la nación argentina (Buenos Aires, 1817-1914), Beatriz Viterbo, Rosario, 1995.

Salvatore, Ricardo, "Sobre el surgimiento del Estado Médico legal en la Argentina, (18901940)", Estudios Sociales, vol. XI, n²0, 2001, p. $81-114$

Scarzanella, Eugenia, Ni gringos ni indios. Inmigración, criminalidad y racismo en Argentina, 1890-1940, Universidad Nacional de Quilmes, Quilmes, 2002.

Seidellan, Gisela, La justicia penal en la provincia de Buenos Aires. Instituciones, prácticas y codificación del derecho (1877-1906), Buenos Aires, Biblos, 2012.

Shapin, Steven, A Social History of Truth. Civility and Science in Seventeenth-Century England, The University of Chicago Press, Chicago, 1994.

Steadman Jones, Gareth, "La postura determinista: algunos obstáculos para el futuro desarrollo de la aproximación lingüística a la historia en los años '90”, Entrepasados, n¹4, 1998, p. 119-139. 